\title{
Upaya Konservasi Arsitektural Pada Stasiun Jakarta Kota
}

\author{
Maria Galuh Wijayanti ${ }^{1}$, Yuni Kartika Sari ${ }^{2}$, Purnamasari ${ }^{3}$, Augustina Ika Widyani ${ }^{4}$ \\ Fakultas Seni Rupa dan Desain, Universitas Tarumanagara \\ Maria.615150119@stu.untar.ac.id
}

\begin{abstract}
Stasiun Jakarta Kota adalah salah satu bangunan cagar budaya yang ada di Jakarta. Stasiun ini ditetapkan sebagai bangunan konservasi karena memiliki nilai historis. Statusnya yang merupakan stasiun aktif sampai hari ini, menuntut adanya upaya untuk menjaga dan merawat keadaan bangunan stasiun. Permasalahan dari penelitian ini adalah untuk mengetahui prinsip dan kriteria pelestarian cagar budaya untuk Stasiun Jakarta Kota, sehingga dapat menganalisa apakah upaya yang telah dilakukan selama ini sudah tepat atau belum. Melalui metode deskriptif komparatif dapat ditemukan hasil penelitian berupa kesesuaian antara prinsip dan kriteria pelestarian cagar budaya dengan upaya konservasi yang telah dilakukan pada Stasiun Jakarta Kota. Tujuannya adalah untuk mengupayakan langkah konservasi sesuai dengan prinsip dan kriteria pelestarian cagar budaya. Hasil dari penelitian ini adalah belum semua prinsip dan kriteria pelestarian cagar budaya diupayakan dengan baik pada Stasiun Jakarta Kota, salah satunya adalah perihal keamanan.
\end{abstract}

Kata kunci: Stasiun Jakarta Kota, Konservasi, Cagar budaya, Arsitektural, Pemerintah

\section{PENDAHULUAN}

Bangsa Indonesia kaya sejarah dan budaya karena faktor sosiologis-historis yang disebabkan oleh masuknya pengaruh dari asing dan faktor geografis yang mengakibatkan adanya keberagaman budaya. Hal ini tentu mempengaruhi kehidupan masyarakat, termasuk di dalamnya adalah bidang arsitektural. Arsitektur masa lalu yang terdiri dari bangunan-bangunan dan kawasankawasan cagar budaya, yang berperan dalam merangkai dan menghubungkan sejarah suatu kota dari masa lalu ke masa sekarang dan masa yang akan datang. Namun, Budihardjo (Sidharta \& dkk, 1989) mengemukakan bahwa arsitektur dan kota di Indonesia saat ini banyak yang kehilangan jejak masa lalu. Hilangnya bangunan kuno bersejarah menandakan lenyapnya pula bagian sejarah dari suatu tempat, yang sebenarnya telah menciptakan suatu identitas tersendiri sehingga timbul erosi identitas budaya.

Untuk mempertahakan warisan budaya Indonesia, perlu dilakukan upaya konservasi, khususnya pada bangunan kuno dan bersejarah. Sampai dengan tahun 2007, di Jakarta terdapat 4 (empat) kawasan cagar budaya, yaitu: Kotatua, Menteng, Kebayoran Baru, dan Situ Babakan. Di dalam kawasankawasan ini terdapat arsitektur kota dan bangunan-bangunan yang harus dilestarikan. Salah satu cagar budaya di kawasan Kotatua adalah Stasiun Jakarta Kota atau JAKK. Stasiun kerata api ini telah ditetapkan sebagai cagar budaya berdasarkan SK Gubernur No. 475 Th. 1999. Stasiun ini memiliki bentuk arsitektural 
yang berkembang pada zamannya, sehingga penting untuk dilakukan pengkajian konservasi terhadap Stasiun Jakarta Kota agar jejak sejarah bangunannya tidak hilang. Untuk menjaga cagar budaya, penting untuk mengetahui apakah upaya konservasi Stasiun Jakarta Kota sudah sesuai atau belum dengan prinsip dan kriteria konservasi bangunan bersejarah. Dengan demikian dapat diketahui dan dianalisis hasilnya sehingga memberikan manfaat bagi khalayak umum.

Nurisjah dan Pramukanto (2001) dalam Hendry (2008), mengemukakan bahwa konservasi merupakan tindakan yang masif dalam upaya pelestarian untuk melindungi suatu landscape bersejarah dari kehilangan atau pelanggaran atau pengaruh yang tidak tepat. Selain itu, Siahaan (2007) menyatakan bahwa pelestarian atau konservasi adalah kegiatan perawatan, pemugaran, dan pemeliharaan bangunan gedung dan lingkungannya untuk mengembalikan keandalan bangunan tersebut sesuai dengan aslinya atau sesuai dengan keadaan menurut periode yang dikehendaki. Artinya konservasi merupakan tindakan perawatan, pemugaran dan pemeliharaan untuk melindungi suatu lingkungan bersejarah dari kehilangan atau pengaruh yang tidak tepat untuk mengembalikan keandalan bangunan sesuai dengan keadaan menurut periode yang dikehendaki. Pada dasarnya kegiatan konservasi terhadap bangunan bersejarah sudah diatur dan dipandu Badan Warisan Dunia di bawah UNESCO dan salah satunya termuat dalam Piagam Burra. Prinsip-prinsip kegiatan Konservasi dan Preservasi (Burra Charter, 2003) adalah: 1) Tujuan akhir konservasi adalah mempertahankan cultural significanc (nilai estetika, sejarah, ilmu pengetahuan dan sosial) sebuah place dan mencakup faktor pengamanan, pemeliharaan dan nasibnya di masa mendatang. 2) Konservasi didasarkan pada rasa penghargaan terhadap kondisi awal material fisik dan sebaiknya dengan intervensi sesedikit mungkin. 3) Konservasi sebaiknya melibatkan semua disiplin ilmu yang dapat memberikan kontribusi terhadap studi dan penyelamatan place. 4) Konservasi sebuah place harus mempertimbangkan seluruh aspek 'signifikansi kultural' tanpa meng-utamakan pada salah satu aspeknya. 5) Konservasi harus dilakukan dengan melalui penyelidikan yang seksama yang diakhiri dengan laporan yang memuat 'signifikansi kultural' yang merupakan prasyarat penting untuk menetapkan kebijakan konservasi. 6) Kebijakan konservasi akan menentukan kegunaan apa yang paling tepat. 7) Konservasi membutuhkan pemeliharaan yang layak terhadap 'visual setting', misalnya: bentuk, skala, warna, tekstur dan material. 8) Sebuah bangunan atau sebuah karya sebaiknya 
dibiarkan di lokasi bersejarahnya. 9) Pemindahan isi yang membentuk bagian dari signifikasi kultural dari sebuah tempat pada dasarnya tidak dapat diterima (Burra Charter, 2003).

Adapun kriteria konservasi bangunan bersejarah bedasarkan Pasal 7 Perda DKI Jakarta No. 2/1999 tentang penentuan bangunan cagar budaya ditetapkan berdasarkan kriteria: 1) Nilai sejarah; 2) Umur; 3) Keaslian; 4) Kelangkaan; 5) Tengeran/ Landmark; 6) Arsitektur.

Kriteria yang dimaksud pada ayat (2) pasal ini bersifat kumulatif alternatif, dengan tolak ukur sebagai berikut: 1) Tolak ukur nilai sejarah, dikaitkan dengan peristiwa-peristiwa perjuangan, ketokohan, politik, sosial, budaya yang menjadi simbol nilai kesejahteraan pada tingkat nasional dan atau Daerah Khusus Ibukota Jakarta. 2) Tolak ukur umur, dikaitkan dengan batas usia sekurang kurangnya 50 (lima puluh) tahun. 3) Tolak ukur keaslian, dikaitkan dengan keutuhan baik sarana dan prasarana lingkungan maupun struktur, material, tapak bangunan dan bangunan didalamnya. 4) Tolak ukur kelangkaan, dikaitkan dengan keberadaannya sebagai satu-satunya atau yang terlengkap dari jenisnya yang masih ada pada lingkungan lokal, nasional atau bahkan dunia. 5) Tolak ukur petanda atau landmark, dikaitkan dengan keberadaan sebuah bangunan tunggal monumen atau bentang alam yang dijadikan simbol dan wakil dari suatu lingkungan sehingga merupakan tanda atau petanda lingkungan tersebut. 6) Tolak ukur arsitektur, dikaitkan dengan estetika dan rancangan yang menggambarkan suatu zaman dan gaya tertentu.

Pada penelitian ini, tolak ukur yang digunakan adalah tolak ukur keaslian. Selanjutnya analisis akan mengacu pada: (1) Pasal 53, ayat 3 mengenai tata cara Pelestarian Cagar Budaya harus mempertimbangkan adanya kemungkinan dilakukannya pengembalian kondisi awal seperti sebelum kegiatan pelestarian; (2) Pasal 53, ayat 4 mengenai pelestarian Cagar Budaya harus didukung oleh kegiatan pendokumentasian sebelum dilakukan kegiatan yang dapat menyebabkan terjadinya perubahan keasliannya; (3) Pasal 61, ayat 1 tentang pengamanan dilakukan untuk menjaga dan mencegah Cagar Budaya agar tidak hilang, rusak, hancur, atau musnah; (4) Pasal 73 tentang perawatan dilakukan dengan pembersihan, pengawetan, dan perbaikan atas kerusakan dengan memperhatikan keaslian bentuk, tata letak, gaya, bahan, atau teknologi Cagar Budaya; (5) Pasal 62, ayat 2a tentang polisi khusus sebagaimana dimaksud pada ayat [1] berwenang: melakukan patroli di kawasan cagar budaya sesuai dengan wilayah hukumnya; (6) Pasal 77, ayat 1 
tengang pemugaran bangunan cagar budaya dan struktur cagar budaya yang rusak dilakukan untuk mengembalikan kondisi fisik dengan cara memperbaiki, memperkuat, konsolidasi, rehabilitasi dan restorasi.

\section{METODE}

Metode pengumpulan data yang digunakan pada penelitian ini menggunakan metode deskriptif komparatif. Metode deskriptif adalah membuat gambaran secara sistematis , gambaran secara sistematis, faktual dan akurat mengenai fakta, sifat serta hubungan antara fenomena yang diselidiki, sedangkan komparatif adalah membandingkan keberadaan satu variabel atau lebih pada dua atau lebih sampel yang berbeda, atau pada waktu yang berbeda yaitu kondisi awal dan kondisi terkini. Metode ini akan dilakukan dengan pendekatan kualitatif yaitu data yang dikumpulkan berdasarkan catatan lapangan; memo; dokumen pribadi dan dokumen resmi berupa undang-undang dan kajian teori, yaitu:

a. Observasi

Melakukan observasi di bangunan utama Stasiun Jakarta Kota dan melalui literatur atau buku yang berhubungan dengan topik dan objek penelitian.

b. Dokumentasi

Melakukan dokumentasi dengan mengumpulkan data arsip/ dokumen terkait dengan ketentuan konservasi dari pemerintah, serta dokumentasi tentang kondisi awal Stasiun Jakarta Kota.

c. Studi Pustaka.

Menggunakan sumber buku yang bersifat teoretik dan dijadikan acuan dalam penelitan serta menggunakan jurnal yang berkaitan dengan konservasi bangunan cagar budaya, stasiun, dan tipologi bangunan.

Sasaran penelitian ini mencakup subjek penelitian berupa kajian upaya koservasi yang telah dilakukan di Stasiun Jakarta Kota. Objek penelitian berupa elemen arsitektural yang mencakup struktur dan bentuk bangunan berdasarkan berbagai tolak ukur. Lokasi penelitian berada di Stasiun Jakarta Kota, yang terletak di Jl. Lada, Pinangsia, Tamansari, Kota Jakarta Barat, 11110.

Variabel penelitian ini yaitu konservasi, kriteria bangunan cagar budaya, prinsip kegiatan konservasi, panduan aturan dalam konservasi cagar budaya, dan upaya dalam melakukan konservasi terhadap bangunan cagar budaya.

Metode pengolahan data yang dipakai pada penelitian ini adalah pengumpulan data, reduksi data, display data, verifikasi data, dan analisis data.

\section{HASIL DAN PEMBAHASAN}

Stasiun akhir untuk KRL ini dibangun pada tahun 1914 dan diresmikan pada 8 Oktober 
1929 (Pratama, 2018). Stasiun ini merupakan karya arsitek Ir. Frans Johan Louwrens Ghijsels dengan langgam Art Deco.

Upaya pelestarian di Jakarta didasarkan kepada UU No. 5 tahun 1992 Tentang Benda Cagar Budaya dan Peraturan Daerah No. 9 tahun 1999, yang menggolongkan kawasan cagar budaya menjadi 3 (tiga) golongan, yaitu: kawasan cagar budaya golongan I sampai dengan III, dan menggolongkan bangunan cagar budaya menjadi 3 (tiga) golongan, yaitu: bangunan cagar budaya golongan $A, B$, dan C.

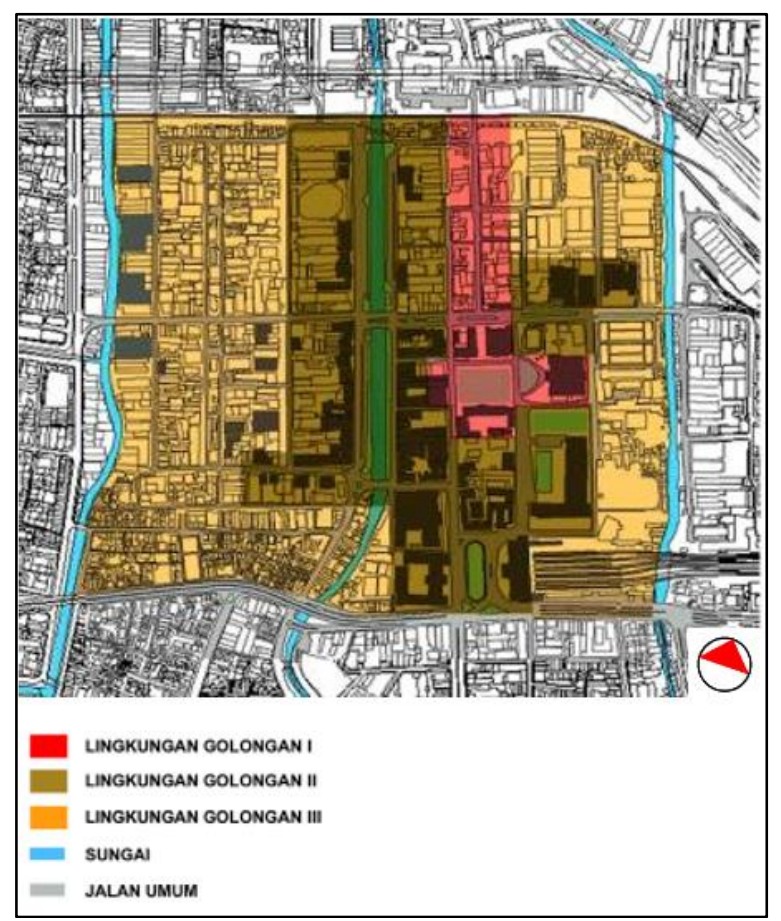

Gambar 1. Penggolongan Lingkungan Cagar Budaya di Kawasan Cagar Budaya Kotatua (Sumber: Guidelines Kota Tua, 2007)

Kawasan Stasiun Jakarta Kota diklasifikasikan sebagai Golongan II, yaitu lingkungan yang hanya memenuhi tiga (3) kriteria. telah mengalami perubahan namun masih memiliki beberapa unsur keaslian.

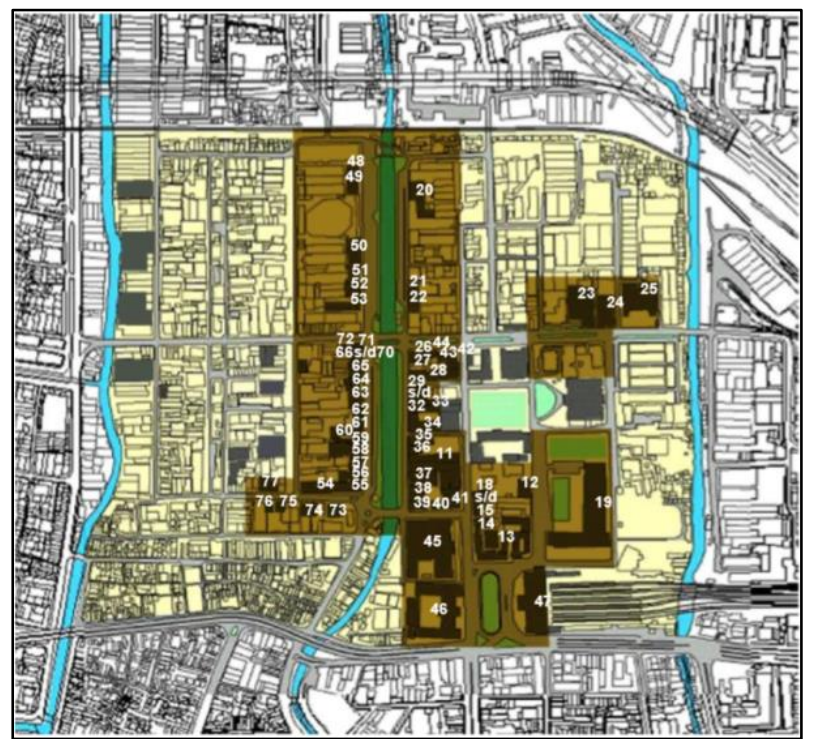

Gambar 2. Lingkungan cagar budaya Golongan II (Sumber: Guidelines Kota Tua, 2007)

Upaya pemerintah dalam melakukan konservasi arsitektural pada Stasiun Jakarta Kota dikaji berdasarkan pasal yang ada. Berikut pengkajian upaya pemerintah dalam konservasi berdasarkan pasal dan fakta yang ada di lapangan:

1. Pasal 53, ayat 3. Tata cara Pelestarian Cagar Budaya harus mempertimbangkan adanya kemungkinan dilakukannya pengembalian kondisi awal seperti sebelum kegiatan pelestarian.

a. Fasad. Pemerintah masih mempertahankan bentuknya tetapi ada sedikit perubahan pada warna dan diletakannya nama bagian stasiun kota. 


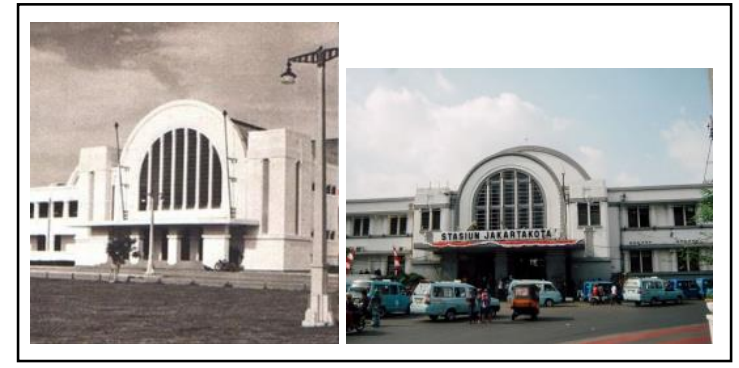

Gambar 3. Perubahan Penambahan Warna dan Penambahan Papan Nama pada Stasiun Jakarta Kota

(Sumber: http://bit.do/fbQpa, 2018)

b. Lobby. Bentuk arsitektural dan penggunaan atap barrel-vault tidak ada yang berubah

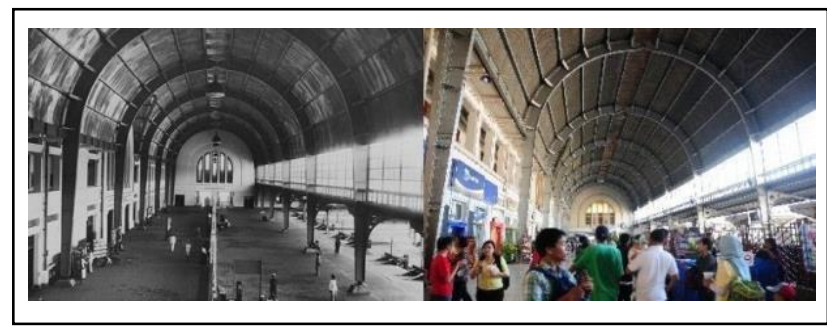

Gambar 4. Bentuk arsitektural dan penggunaan atap barrelvault Stasiun Jakarta Kota

(Sumber: : https://cdn-image.hipwee.com/wpcontent/uploads/2014/04/Jakartakota.jpg, 2018)

2. Pasal 53, ayat 4. Pelestarian Cagar Budaya harus didukung oleh kegiatan pendokumentasian sebelum dilakukan kegiatan yang dapat menyebabkan terjadinya perubahan keasliannya.

Upaya pelestarian yang sudah dilakukan adalah Pihak Stasiun Jakarta Kota sudah melakukan kegiatan pendokumentasian sebelum melakukan kegiatan perubahan dari yang asli. Hal itu dibuktikan banyaknya hasil dokumentasi berupa foto pada masa awal pembangunan dan pada area-area yang dilakukan pergantian, misalnya pada area lobby utama yang dilakukan pergantian material lantai.

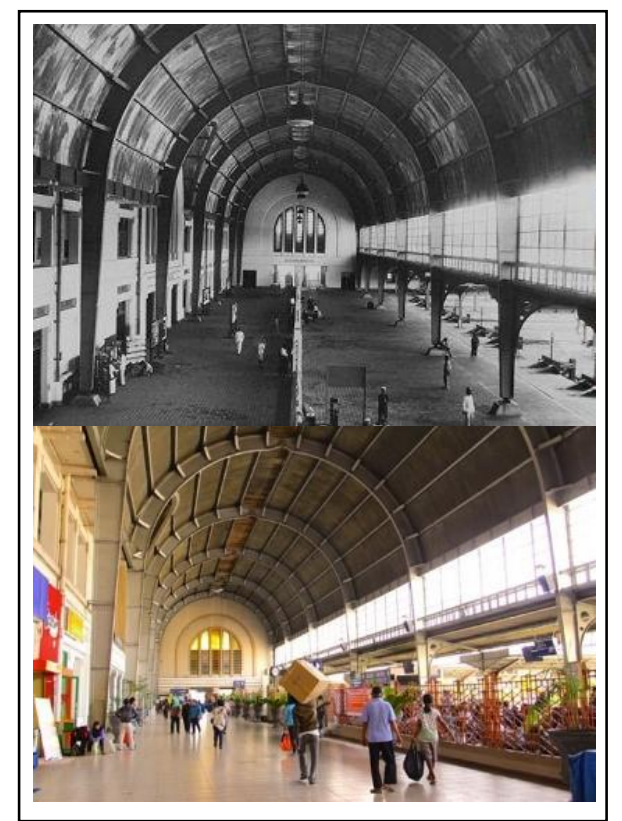

Gambar 5. Bentuk arsitektural dan penggunaan atap barrelvault Stasiun Jakarta Kota

(Sumber: https://cdn-image.hipwee.com/wpcontent/uploads/2014/04/Jakartakota.jpg, 2018)

3. Pasal 61, ayat 1 . Pengamanan dilakukan untuk menjaga dan mencegah Cagar Budaya agar tidak hilang, rusak, hancur, atau musnah.

Upaya pelestarian yang sudah dilakukan adalah pengamanan yang dilakukan oleh pihak PT. KAI pada bangunan stasiun yang dapat dikatakan minim karena PT. KAI lebih berfokus pada pengamanan internal, seperti tingkat kerawanan tindak kriminal yang terjadi di area stasiun maupun gerbong KRL.

4. Pasal 73. Perawatan dilakukan dengan pembersihan, pengawetan, dan perbaikan atas kerusakan dengan memperhatikan keaslian bentuk, tata letak, gaya, bahan, atau teknologi Cagar Budaya. 
Upaya Pelestarian yang sudah dilakukan:

a. Pihak Stasiun Jakarta Kota sudah memenuhi upaya pelestarian yang terdapat pada pasal 73 , di mana pihak stasiun menggunakan lantai keramik berwarna krem, yang memberi nuansa klasik namun tetap bersih. Upaya ini dilakukan untuk mempertahankan gaya Art Deco seperti yang dibuat oleh arsiteknya.

b. Fasad: Pemerintah masih mempertahankan bentuknya tetapi ada sedikit perubahan pada warna dan diletakkannya nama bagian stasiun kota.

c. Pembersihan dilakukan dalam menertibkan kios-kios di dalam stasiun yang berjubel, kini hanya tinggal beberapa saja. Ruang yang ditinggalkan kini difungsikan untuk kebutuhan ruang kantor PT Kereta Api, dan menghidupkan jalur /rel kereta api yang telah lama mati (2001) dengan membersihkan jalur tersebut dari pemukiman-pemukiman liar yang kumuh.

5. Pasal 62, ayat 2a. Polisi khusus sebagaimana dimaksud pada ayat (1) berwenang: melakukan patroli di kawasan cagar budaya sesuai dengan wilayah hukumnya.

Upaya pelestarian yang dilakukan hanya ada Kepolisian Sektor Metro Taman Sari Resort Metro Jakarta Barat yang terbukti melakukan patroli di area Stasiun Jakarta
Kota. Namun patroli tersebut bukan bertujuan untuk melindungi cagar budaya melainkan menjaga keadaan stasiun Jakarta Kota tetap kondusif.

6. Pasal 77, ayat 1. Pemugaran bangunan cagar budaya dan struktur cagar budaya yang rusak dilakukan untuk mengembalikan kondisi fisik dengan cara memperbaiki, memperkuat, konsolidasi, rehabilitasi dan restorasi.

Upaya pelestarian yang telah dilakukan adalah pemerintah mengupayakan perbaikan pada area ruang tunggu peron setelah inseden pada tanggal 26 Desember 2014 pukul 06.30, lokomotif CC201 8907 menabrak peron di Stasiun Jakarta Kota, pada saat melangsir rangkaian kereta api Argo Parahyangan. Lokomotif tersebut melampaui batas aman berhenti, sehingga meloncat keluar rel kemudian menggerus lantai peron. Tidak ada korban jiwa dalam peristiwa ini.

\section{SIMPULAN}

Upaya yang dilakukan pemerintah berdasarkan perda masih belum semuanya dilakukan sesuai dengan pasal yang ada seperti minimnya pengamanan dilakukan untuk menjaga dan mencegah Cagar Budaya agar tidak hilang, rusak, hancur, atau musnah.

Dari penelitian ini dapat mengetahui tingkatan kelas dan golongan dari cagar 
budaya berupa bangunan Stasiun Jakarta Kota dan mengapa mendapatkan kelas dan golongan tersebut. Penelitian selanjutnya dapat disarankan untuk mengetahui motivasi atau tujuan pengunjung mendatangi Stasiun Jakarta Kota sebagai objek cagar budaya yang harus dipelihara bukan hanya sebagai stasiun akhir KRL.

\section{DAFTAR PUSTAKA}

- Pemerintah Provinsi DKI Jakarta Dinas Kebudayaan dan permuseuman, "Guidelines Kota Tua", 2007

Peraturan Pemerintah Daerah DKI Jakarta No. 9 Tahun 1999, tentang

Pelestarian dan Pemanfaatan Lingkungan dan bangunan Cagar Budaya

Burra Charter. 2003. Pedoman dan Prinsipprinsip Preservasi dan Konserrvasi Bangunan dan Lingkungan Bersejarah - Burra Charter, World Harritage Council UNESCO Publisher, Paris.

Issemiarti, Siti Madichah. 2011. "Revitalisasi Bangunan Lama Sebagai Upaya Konservasi Kota". Yogyakarta. Jurnal Arsitektur KOMPOSISI, Volume 9, No 1.

Marquies, K., \& Walker, M. (1996). The Illustrated BURRA CHARTER: Making Good Decisions About the Care of Important Places. Australia: icomos.

Pawitro, Udjianto. 2015. Preservasi Konservasi Bangunan Bersejarah Dan Pengelolaan Kawasan Kota Lama. Bandung. Prosiding Simposium Nasional RAPI XIV - 2015 FT UMS.
Sidharta, \& dkk. (1989). Konservasi Lingkungan dan Bangunan Kuno Berserjarah di Surakarta. Yogyakarta: Gajah Mada University Press.

Sutanto, Sucliany. 2015. Analisa Kriteria Bangunan Bersejarah. Departemen Arsitektur. Fakultas Teknik. Universitas Sumatera Utara. Medan.

Pratama, A. N. (2018, 08 10). megapolitan.kompas.com. Retrieved from Kompas.com: https://megapolitan.kompas.com/rea d/2018/10/08/10454201/hari-inidalam-sejarah-stasiun-beosdiresmikan-kini-jadi-jakartakota?page=all 